Jpn. J. Genet. (1986) 61, pp. 119-126

\title{
Location of fourth chromosomal male-determining factors of the housefly, Musca domestica
}

\author{
By Hiroaki InouE* Takashi Tomita* and Toshiki Hiroyoshi* \\ * Department of Genetics, Osaka University Medical School, \\ 3-57, Nakanoshima 4 chome, Kita-ku, Osaka 530 \\ * Department of Medical Entomology, National Insitute of Health, \\ Kamiosaki, Shinagawa-ku, Tokyo 141 \\ (Received February 10, 1986)
}

\begin{abstract}
Two novel fourth chromosomal male-determining factors, IV $^{\mathrm{M}}$, of the housefly were mapped using a modification of the general mapping procedure for autosomal male-determining factors, $\mathrm{A}^{\mathrm{M}}$ (Inoue and Hiroyoshi 1984). On the basis of meiotic female recombination frequencies, the same gene order Barl-ye- $M$ was demonstrated for the two IV ${ }^{M}$ chromosomes. On both chromosomes, male recombination took place although at exceedingly low frequencies. From a comparison between the female and the male recombination maps, it appears that, unlike other $\mathrm{A}^{\mathrm{M}}$ factors examined so far, the two $\mathrm{IV}^{\mathrm{M}}$ factors are not located near the centromere.
\end{abstract}

\section{INTRODUCTION}

Earlier cytological observations of the housefly, Musca domestica L., have revealed that there are five pairs of autosomes and a pair of heterochromatic sex-chromosomes, XX in the female and XY in the male (Stevens 1908; Perje 1948). In such conventional XX-XY strains, the sex is determined by the presence or absence of the $\mathrm{Y}$ chromosome, because the $\mathrm{Y}$ carries an epistatic male-determining factor, $M$, whereas the $\mathrm{X}$ plays no important roles on the sex determination (Hiroyoshi 1964; Rubini and Palenzona 1967). In certain laboratory and natural strains, however, neither females nor males have the $\mathrm{Y}$ chromosome. Instead, these males carry an autosomal male-determining factor, $\mathrm{A}^{\mathrm{M}}$, of different linkage groups (e.g., Sullivan 1958; Wagoner 1969; Hiroyoshi and Inoue 1979; Tomita and Wada 1985), or an X chromosomal $M$ factor, $\mathrm{X}^{\mathrm{M}}$ (Denholm et al. 1983). The $\mathrm{A}^{\mathrm{M}}$ factors are designated as $\mathrm{I}^{\mathrm{M}}, \mathrm{II}^{\mathrm{M}}$ and so on, according to their linkage groups.

This phenomenon, referred to as $M$-factor polymorphism, has also been reported in several other dipteran species, including Megaselia scalaris (Tokunaga 1955; Mainx 1964), Culex tritaeniorhynchus (Baker and Sakai 1976), Chironomus tentans (Beerman 1955), Ch. nuditarsus, Ch. pulmosus (Rosin and Fischer 1972), Ch. oppositus and Ch. australis (Martin et al. 1980; Martin and Lee 1984). Transposition of $M$ factors mediated by a transposable element(s) has been suggested as a cause of $M$ factor polymorphism (Green 1980). 
It would be interesting to locate as many $M$ factors of different geographic origins as possible to see if $\mathrm{A}^{\mathrm{M}}$ factors belonging to the same linkage group all occupy a single site or if they are located at many different sites. The results might shed light on the origin of $M$ polymorphism in $M$. domestica.

Usually, the $\mathrm{A}^{\mathrm{M}}$ factors of $M$. domestica are difficult to locate, because little or no recombination takes place in the male. Earlier, two laborious approaches have been made to map the $\mathrm{A}^{\mathrm{M}}$ factors: one approach made use of exceptional male-recombinations (Inoue and Hiroyoshi 1982; Hiroyoshi, Fukumori and Inoue 1982) and the other employed both genetic and cytological analyses (Rubini and Franco 1972; Rovati et al. 1983). Recently, we have developed an efficient procedure for mapping the $\mathrm{A}^{\mathrm{M}}$ factors, and have demonstrated that three $\mathrm{I}^{\mathrm{M}}$, four $\mathrm{II}^{\mathrm{M}}$, twelve $\mathrm{III}^{\mathrm{M}}$ and three $\mathrm{V}^{\mathrm{M}}$ factors of different geographic origins are all located at a single or closely linked site(s) on the respective autosomes (Inoue, Fukumori and Hiroyoshi 1983; Inoue and Hiroyoshi 1984). Until recently, no IV $^{\mathrm{M}}$ factors were known to exist. The discovery of two IV ${ }^{\mathrm{M}}$ chromosomes from Japanese populations (Tomita and Wada 1985) thus demanded these $M$ factors to be located.

\section{MATERIALS AND METHODS}

\section{Housefly strains}

Genetic markers used in this study were $b w b$ (brown body, autosome 3 ), $B a$ (Bald abdomen, autosome 4), $r l$ (rolled wing, probably an allele of $c y w$, curly wing, autosome 4), ye (yellow eye, autosome 4). These markers were originally kept in the conventional XX-XY strains, but they were introduced into an $\mathrm{A}^{\mathrm{M}}$ or an $F$ strain for experimental purposes.

Two Japanese $\mathrm{IV}^{\mathrm{M}}$ strains, Aio and Okinawa, were used for the location of $\mathrm{IV}^{\mathrm{M}}$ factors. These strains were established in 1984 from a single male collected from Okinawa and a single male collected from Aio, Yamaguchi pref., respectively (Tomita and Wada 1985), and had been maintained in mass for approximately 10 generations before use. A previously synthesized $F$ strain carrying the $F$ factor marked with $B a$ (Inoue and Hiroyoshi 1984) was maintained by mating $\mathrm{II}^{\mathrm{M}} / \mathrm{II}^{\mathrm{M}} ; b w b / b w b ; B a F /++$ females and $\mathrm{II}^{\mathrm{M}} / \mathrm{II}^{\mathrm{M}} ; b w b /$ $b w b ;++1++$ males. A III ${ }^{\mathrm{M}}$ strain carrying marker genes on the autosomes 3 and 4 was maintained by mating $b w b+|b w b+; B a r l y e|+r l$ ye females and $b w b+\mid b w b \mathrm{III}^{\mathrm{M}} ; B a$ rl ye $\mid+r l$ ye males.

Flies were raised at $24 \pm 1^{\circ} \mathrm{C}$ under uncrowded conditions. The rearing method and the linkage relationships of marker genes are given by Hiroyoshi (1977).

A procedure for mapping $\mathrm{IV}^{\mathrm{M}}$ factors by means of female recombination

A procedure described below is an application of the general procedure for 


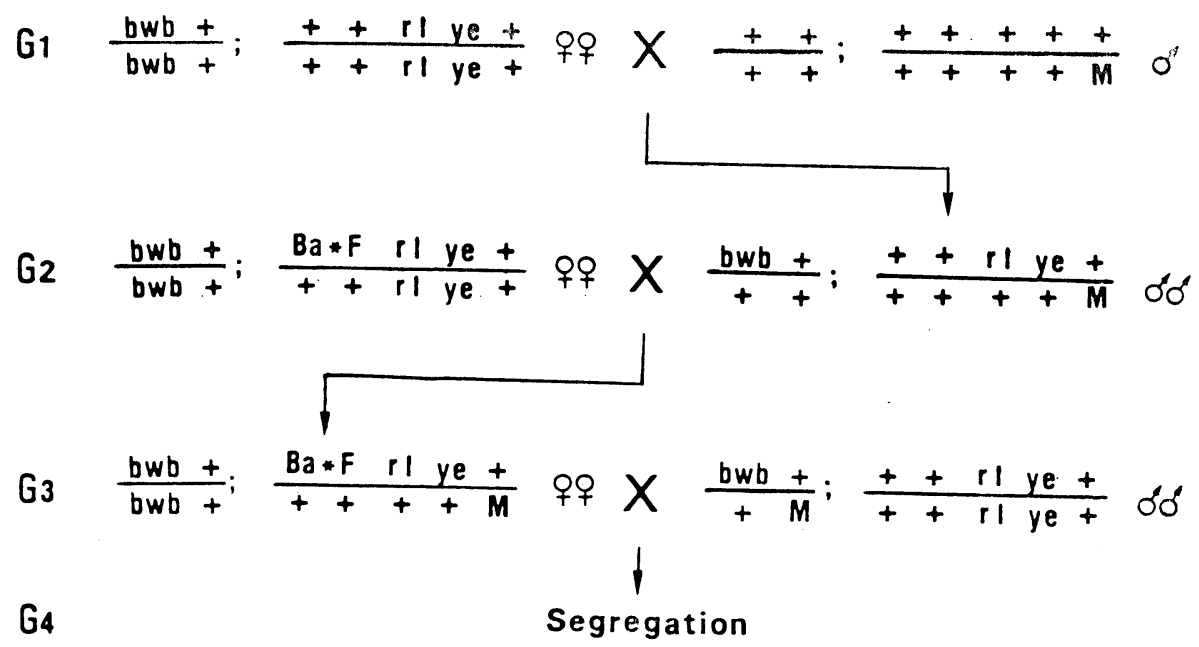

Fig. 1. A mating scheme used to map IVM factors of Musca domestica. The gene order of two closely linked genes, $B a$ and $F$, has not yet been determined, and thus designated as $B a^{*} F$. The linkage groups are given in the $3 ; 4$ order.

mapping autosomal male-determining factors (Inoue and Hiroyoshi 1984) to the $M$ factors on autosome 4. It makes use of an $F$ factor isolated from a female heterogametic strain. The $F$ factor, first reported by Rubini (1977), is a dominant sex-transformation gene that overrides a genotypic male carrying one or more $M$ factors to develop into a fertile female. In such phenotypic females, meiotic recombination takes place at the same or similar frequencies as compared with the conventional XX females (Rubini and Franco 1972; Inoue, Fukumori and Hiroyoshi 1983). The $F$ factor is located on autosome 4 in close linkage with the $B a$ locus (McDonald et al. 1978). Altogether, the use of $F$ factor marked with $B a$ to transform $M$-carrying males into fertile females permits one to locate the $M$ factor by means of female recombination.

An $F$ strain for mapping IV $^{\mathrm{M}}$ factors was synthesized as follows. It should be noted that the gene order of two closely linked genes, $B a$ and $F$, still remained to be determined due to the lack of flanking marker genes. Therefore, they are symbolized as $B a^{*} F$. $\mathrm{II}^{\mathrm{M}} / \mathrm{II}^{\mathrm{M}} ; b w b+/ b w b+; B a^{*} F++1$ ++++ females from the synthetic $F$ strain were mated with $+/+; b w b$ $+/+\mathrm{III}^{\mathrm{M}} ;++r l$ ye/ $++r l$ ye males from the $\mathrm{III}^{\mathrm{M}}$ strain, and the resulting $\mathrm{F}_{1}$ females, $\mathrm{II}^{\mathrm{M}} /+; b w b+/ b w b+; B a^{*} F++/++r l$ ye, backcrossed to the $+/+; b w b+1+\mathrm{III}^{\mathrm{M}} ;++r l y e /++r l$ ye males. In the $\mathrm{F}_{2}, \mathrm{II}^{\mathrm{M}} /+$ or $+/+; b w b+\left|b w b+; B a^{*} F r l y e\right|++r l$ ye females were collected and individually mated with the $+/+; b w b+/+\mathrm{III}^{\mathrm{M}} ;++r l$ ye $/++r l$ ye males in order to check whether these females carried $\mathrm{II}^{\mathrm{M}}$ or not. In the $\mathrm{F}_{3}, b w b+1$ $b w b+; B a^{*} F r l y e l++r l$ ye females and $b w b+\mid+\mathrm{III}^{\mathrm{M}} ;++r l y e /++$ 
$r l$ ye males were collected only when no $b w b$ sib males appeared, which ensured the absence of $\mathrm{II}^{\mathrm{M}}$ in these flies. In and after the $\mathrm{F}_{4}$, four types of flies would be recovered; i.e., (1) $b w b+\left|b w b+; B a^{*} F r l y e\right|++r l$ ye females, (2) $b w b+|b w b+;++r l y e|++r l$ ye females, (3) $b w b+/+\mathrm{III}^{\mathrm{M}} ; B a^{*} \boldsymbol{F} r l$ $y e /++r l$ ye females and (4) $b w b+/+\mathrm{III}^{\mathrm{M}} ;++r l y e /++r l$ ye males. Of these, flies (1) and (4) were selected to maintain the stock.

Figure 1 gives a mating scheme used to map IV $^{\mathrm{M}}$ factors by means of female recombination. In the $G_{4}$, four types of flies should segregate with respect to the $b w b$ and the $B a$ phenotypes; i.e., (1) +; $+(2)+; B a(3) b w b$; + and (4) $b w b ; B a$. Of these, the $B$ a progeny would be recovered as females, because they should carry $F$ which is epistatic to $M$ factors. The $b w b^{+} ; B a^{+}$ progeny would be recovered as males, because they should carry III $^{\mathrm{M}}$ in the absence of $F$. It is the $b w b ; B a^{+}$progeny of which sex determination would exclusively depend on the presence or absence of IV ${ }^{\mathrm{M}}$, because they should carry neither $F$ nor III $^{\mathrm{M}}$. Therefore, the recombination frequencies between $\mathrm{IV}^{\mathrm{M}}$ and marker genes, $B a, r l$ and $y e$, were calculated using flies of this class.

\section{Male-recombination studies of IV $^{\mathrm{M}}$ chromosomes}

In order to see the occurrence of male-recombination along the $\mathrm{IV}^{\mathrm{M}}$ chromosomes of the Aio and the Okinawa strains, males from each of the strains were mated with $B a r l y e+1+r l$ ye + females. The $\mathrm{F}_{1}$ males, $B a r l$ ye $+/+++M$, were individually mated with 6 to $8+r l$ ye $+/+r l$ ye + females, and the resulting $\mathrm{F}_{2}$ flies were scored with respect to sex and the marker phenotypes. All flies with recombinant phenotypes were mated with $b w b+/ b w b+;+r l y e+1+r l y e+$ females or $b w b+1+\mathrm{III}^{\mathrm{M}} ;+r l y e+1+$ $r l y e+$ males, and their genotypes confirmed.

\section{RESULTS}

According to the mating scheme shown in Figure 1, locations of $M$ factors of two Japanese IV ${ }^{\mathrm{M}}$ strains, Aio and Okinawa, were determined. In each strain, two $\mathrm{IV}^{\mathrm{M}}$ chromosomes were individually examined for the locations of $M$ factors. Because no significant differences in the recombination frequencies were observed within a strain, pooled data are presented in Table 1.

Detailed explanation will be given for the Aio strain. As expected (see Fig. 1 and explanation in text), all but one $B a$ progeny were recovered as females, and all $b w b^{+} ; B a^{+}$progeny were males. The subsequent genetic tests revealed that the exceptional $B a$ male was produced by a recombination between $B a$ and $F$ in the $\mathrm{G}_{3}$ females. Using the $b w b ; B a^{+}$progeny of which sex-determination should exclusively depend on the presence or absence of $\mathrm{IV}^{\mathrm{M}}$, we calculated the recombination frequencies along the IV ${ }^{\mathrm{M}}$ chromosome as follows: 
Table 1. Segregations from crosses between bwb+/bwb+;Ba*F rl $y e+1++++M$ famales and bwb $+1+M ;++r l$ $y e+1++r l y e+$ males

\begin{tabular}{|c|c|c|c|c|c|c|c|}
\hline \multirow{2}{*}{\multicolumn{4}{|c|}{$\begin{array}{l}\text { Name of strains } \\
\text { Phenotypes }(3 ; 4)\end{array}$}} & \multicolumn{2}{|c|}{ Aio } & \multicolumn{2}{|c|}{ Okinawa } \\
\hline & & & & \multirow{2}{*}{$\frac{\text { 우 }}{0}$} & \multirow{2}{*}{$\frac{\hat{\delta}}{273}$} & \multirow{2}{*}{$\frac{\text { 우 }}{0}$} & \multirow{2}{*}{$\frac{\hat{\rho}}{292}$} \\
\hline$+;$ & + & + & + & & & & \\
\hline$+;$ & + & + & ye & 0 & 84 & 0 & 89 \\
\hline+ ; & + & $\mathrm{rl}$ & + & 0 & 6 & 0 & 6 \\
\hline$+;$ & + & $\mathrm{rl}$ & ye & 0 & 152 & 0 & 140 \\
\hline$+;$ & $\mathrm{Ba}$ & + & + & 161 & 0 & 157 & \\
\hline+ & $\mathrm{Ba}$ & + & ye & 5 & 0 & 7 & \\
\hline+ ; & $\mathrm{Ba}$ & $\mathrm{rl}$ & + & 75 & 0 & 99 & \\
\hline+ & $\mathrm{Ba}$ & $\mathrm{rl}$ & ye & 249 & $1 *$ & 230 & 0 \\
\hline bwb; & + & + & + & 22 & 213 & 26 & 247 \\
\hline bwb; & + & + & ye & 65 & 0 & 79 & \\
\hline bwb; & + & $\mathrm{rl}$ & + & 0 & 13 & 0 & \\
\hline bwb; & + & $\mathrm{rl}$ & ye & 139 & 11 & 128 & 15 \\
\hline bwb; & $\mathrm{Ba}$ & + & + & 132 & 0 & 152 & \\
\hline bwb; & $\mathrm{Ba}$ & + & ye & 5 & 0 & 2 & \\
\hline bwb; & $\mathrm{Ba}$ & $\mathrm{rl}$ & + & 56 & 0 & 78 & \\
\hline bwb; & $\mathrm{Ba}$ & $\mathrm{rl}$ & ye & 216 & 0 & 227 & \\
\hline \multicolumn{4}{|c|}{ Total } & \multicolumn{2}{|c|}{1,878} & \multicolumn{2}{|c|}{1,983} \\
\hline \multicolumn{8}{|c|}{ Recombination frequencies (\%) } \\
\hline \multicolumn{4}{|c|}{$B a-r l$} & \multicolumn{2}{|c|}{35.2} & \multicolumn{2}{|c|}{30.0} \\
\hline \multicolumn{4}{|c|}{$r l$-ye } & \multicolumn{2}{|c|}{16.8} & \multicolumn{2}{|c|}{17.5} \\
\hline \multicolumn{4}{|c|}{$y e-M$} & \multicolumn{2}{|c|}{7.1} & \multicolumn{2}{|c|}{8.3} \\
\hline
\end{tabular}

* A product of female recombination between $B a$ and $F$.

$B a-r l:(139+13+11 / 22+65+139+213+13+11) \times 100=35.2 \%$ $r l$-ye: $(65+13 / 463) \times 100=16.8 \%$

ye-M: $(22+11 / 463) \times 100=7.1 \%$.

Similar results were obtained for the Okinawa strain.

Table 2 gives the results of male-recombination experiments for the IV ${ }^{\mathrm{M}}$ chromosomes of the Aio and the Okinawa strains. In the Aio strain, $112 \mathrm{Ba}$ $r l$ ye $+/+++M$ males, individually mated to several $+r l$ ye $+1+r l$ ye + females, produced a total of 37,044 flies, in which 51 recombinants and 12 mosaic flies were identified. Of the 51 recombinants, $4+++$ females and 5 $B a r l$ ye males were recovered from a single male, suggesting that these reciprocal recombinants resulted from a single mitotic recombination in a spermatogonial cell and the subsequent proliferations. For the calculation of recombination frequencies, these recombinants were regarded as $1+++$ female and $1 \mathrm{Ba} \mathrm{rl}$ ye male, and the mosaic flies were excluded. Recombina- 
Table 2. Segregations from crosses cetween $+r l$ ye $+/+r l$ ye + females and single $B a r l$ ye $+1+++M$ male

\begin{tabular}{|c|c|c|c|c|c|}
\hline \multicolumn{2}{|c|}{ Name of strains } & \multicolumn{2}{|c|}{ Aio } & \multicolumn{2}{|c|}{ Okinawa } \\
\hline \multicolumn{2}{|c|}{ Males examined $(\mathrm{N})$} & \multicolumn{2}{|c|}{102} & \multicolumn{2}{|c|}{103} \\
\hline \multicolumn{2}{|c|}{ Phenotypes } & 우 & $\hat{\delta}$ & 우 & $\hat{\sigma}$ \\
\hline+ & + & $7(4) *$ & 18,678 & 3 & 25,148 \\
\hline+ & ye & 4 & 0 & 3 & 0 \\
\hline$+\quad \mathrm{rl}$ & + & 0 & 0 & 0 & 0 \\
\hline$+\quad \mathrm{rl}$ & ye & 15 & 0 & 9 & 0 \\
\hline $\mathrm{Ba}$ & + & 0 & 19 & 0 & 7 \\
\hline $\mathrm{Ba}+$ & ye & 0 & 0 & 0 & 0 \\
\hline $\mathrm{Ba} \quad \mathrm{rl}$ & + & 0 & 0 & 0 & 0 \\
\hline $\mathrm{Ba} \quad \mathrm{rl}$ & ye & 18,303 & $6(2) *$ & 24,963 & 1 \\
\hline \multicolumn{2}{|l|}{ Mosaics } & \multicolumn{2}{|r|}{12} & \multicolumn{2}{|r|}{19} \\
\hline \multicolumn{2}{|c|}{ Total } & \multicolumn{2}{|c|}{37,044} & \multicolumn{2}{|c|}{50,129} \\
\hline
\end{tabular}

Recombination frequencies $(\%)$

$\begin{array}{lll}B a-r l & 0.090 & 0.032 \\ r l-y e & 0.011 & 0.006 \\ y e-M & 0.016 & 0.008\end{array}$

* Figures in parentheses represent adjusted numbers of recombinants; i. e., four of the seven +++ females and five of the six $B a r l$ ye males recovered from one male parent were regarded as one +++ female and one $B a r l$ ye male, respectively.

tion frequencies were similarly calculated for the Okinawa strain.

In both strains, the same gene order, $B a-r l-y e-M$, was demonstrated for the IV ${ }^{\mathrm{M}}$ chromosome. When compared between the $B a-M$ interval, the recombination frequency along the $\mathrm{IV}^{\mathrm{M}}$ chromosome of the Aio strain was 2.6 times higher than that of the Okinawa strain $(44 / 37,025$ vs. $23 / 50,110)$. On the basis of the statistical tables of Kastenbaum and Bowman (1970), this difference is significant at the $1 \%$ level. However, the distributions of recmbinants along the IV ${ }^{\mathrm{M}}$ chromosome were similar between the strains; ie., the $B a-r l$ vs. the $r l-M$ intervals (34:10 vs. $\left.16: 7, \chi^{2}=0.474, \mathrm{p}>0.50\right)$ and the $r l$-ye vs. the $y e-M$ intervals ( $4: 6$ vs. $3: 4, \mathrm{P}=0.647$, Fischer's exact probability test).

\section{DISCUSSION}

The general procedure for mapping autosomal male-determining factors, $\mathrm{A}^{\mathrm{M}}$,of Musca domestica (Inoue and Hiroyoshi 1984) makes use of a sex-transformation gene, $F$, marked with $B \mathrm{a}$, and thus enables one to locate any $\mathrm{A}^{\mathrm{M}}$ factor by means of female recombination.

Employing a modification of this procedure, we have constructed the 
female recombination maps of $\mathrm{IV}^{\mathrm{M}}$ chromosome of two Japanese $\mathrm{IV}^{\mathrm{M}}$ strains, Aio and Okinawa. These chromosomes both have the gene order, Ba-rl-ye$M$, with similar map distances (Table 1). These results, together with the previous results for the other $\mathrm{A}^{\mathrm{M}}$ chromosomes (Inoue, Fukumori and Hiroyoshi 1983; Inoue and Hiroyoshi 1984), suggest that the $\mathrm{A}^{\mathrm{M}}$ factors are all located at a single or closely linked site(s) on the respective autosomes.

The occurrences of male-recombination, although normally at exceedingly low frequencies, have been observed for the $\mathrm{IV}^{\mathrm{M}}$ chromosomes of the $A i \mathrm{i}$ and the Okinawa strains (Table 2). The relative lengths between the three intervals on the IV ${ }^{\mathrm{M}}$ chromosomes were similar between the strains, but the frequencies differed significantly. This difference probably reflects the effect of genetic backgrounds on the recombination frequencies. Most of the recombinants were recovered singly (51/74) or in clusters of two identical. recombinants $(14 / 74)$, suggesting that male-recombination takes place mostly at the meiotic cell stage. Similar results have been observed among the $\mathrm{I}^{\mathrm{M}}$ chromosomes of Fijian origin (Inoue and Hiroyoshi 1982). However, the very recovery of clusters of reciprocal recombinants (9/74), $4+++$ females and $5 \mathrm{Ba} \mathrm{rl}$ ye males (Table 2), indicates that male recombination could also occur in spermatogonial cells.

In the previous study, we have compared the female and the male recombination maps of identical $\mathrm{A}^{\mathrm{M}}$ chromosomes, and have noted that the two maps differed greatly near the $M$ loci due to the lack of female recombination in these regions, and thus have proposed that the $\mathrm{A}^{\mathrm{M}}$ factors of $M$. domestica are located in the centromeric heterochromatin (Inoue, Fukumori and Hiroyoshi 1983). Inoue and Hiroyoshi (1984) have further showed that the position of $\mathrm{A}^{\mathrm{M}}$ loci on the linkage map of Hiroyoshi (1977) roughly corresponded with the position of centromeres of autosomes given by Wagoner (1967). However, this seems not to be the case for the IV ${ }^{\mathrm{M}}$ factors. The IV ${ }^{\mathrm{M}}$ factors are located most distally of all the genes so far identified on autosome 4, since they were mapped at 7.1-8.3 centimorgans apart from ye (Table 1 and the linkage map of Hiroyoshi 1977). Moreover, the female and the male recombination maps of $\mathrm{IV}^{\mathrm{M}}$ chromosomes differed between $B a$ and $r l$ rather than between ye and $M$ (cf. Table 1 and 2). These two lines of evidence might suggest that the IV $^{\mathrm{M}}$ factors are located somewhere apart from the centromere.

This study was partly supported by Grants-in-Aid from the Ministry of Education, Science and Culture, Japan. We thank Dr. K. Oishi of Kobe University for critical reading of the manuscript. Thanks are also given to Ms. R. Inoue for technical assistance.

\section{REFERENCES}

BAKER, R. H. and SAKAI, R. K. (1976) Male determining factor in the mosquito Culex tritaeniorhynchus. J. Hered. 67, 289-294. 
BeERman, W. (1955) Geschlechtsbestimmung und Evolution der genntischen Y-chromosom bei Chironomus. Biol. Zentralbl. 74, 525-544.

Denholm, I., Franco, M. G., Rubini, P. G. and Vecchi, M. (1983) Identification of a male deteminant on the X chromosome of housefly (Musca domestica L.) populations in South-East England. Genet. Res. Camb, 42, 311-322.

Green, M. M. (1980) Transposable elements in Drosophila and other diptera. Ann. Rev. Genet. 14, $109-120$.

Hiroyoshi, T. (1964) Sex-limited inheritance and abnormal sex ratio in strains of the housefly. Genetics 50, 373-385.

Hiroyoshi, T. (1977) Some new mutants and revised linkage maps of the housefly, Musca domestica Jpn. J. Genet. 52, 275-288.

Hiroyoshi, T., Fukumori, Y. and Inoue, H. (1983) Male crossing-over and location of the male determining factor on the third chromosome in a $\mathrm{III}^{\mathrm{M}}$ strain of the housefly. Jpn. J. Genet. $57,231-239$.

Hiroyoshi, T. and Inoue H. (1979) On the IM-chromosome of the housefly. Jpn. J. Genet. 54, 434.

Inoue, H., Fukumori, Y. and Hiroyoshi, T. (1983) Mapping of autosomal male-determining factors of the housefly, Musca domestica L., by means of sex-reversal. Jpn. J. Genet. 58, 451-461.

Inoue, H. and Hiroyoshi, T. (1982) A male-determining factor on autosome 1 and occurrence of male-recombination in the housefly, Musca domentica L. Jpn. J. Genet. 57, 221-229.

Inoue, H. and Hiroyoshi, T. (1984) Mapping of autosomal male-determining factors of the housefly, Musca domestica L., by using a female-determining factor. Jpn. J. Genet. 59, 453-464.

Kastenbaum, M. A. and Bowman, K. O. (1970) Tables for determining the statistical significance of mutation frequencies. Mutation Res. 9, 527-549.

MaInx, F. (1964) The genetics of Megaselia scalaris Loew (Phoridae): A new type of sex determination in Diptera. Am. Nat. 98, 415-430.

Martin, J., Kuvangkadilok, C., Peart D. H. and Lee, B. T. O. (1980) Multiple sex determining regions in a group of related Chironomus species (Diptera: Chironomidae). Heredity 44, $367-382$.

Martin, J. and LeE, B. T. O. (1984) A phylogenetic study of sex determiner location in a group of Australian Chironomus species (Diptera, Chironomidae). Chromosoma 90, 190-197.

McDonald, I. C., Evenson, P., Nickel, C. A. and Johnson, O. A. (1978) House fly genetics: Isolation of a female determining factor on chromosome 4. Ann. Éntomol. Soc. Am. 71, 692-694.

PerJe, A. M. (1948) Studies on the spermatogenesis in Musca domestica. Hereditas 34, 209-232.

Rosin, S. and Fischer, J. (1972) Polymorphismus des Realisators für mannliches Geschlecht bei Chironomus. Rev. Suisse Zool. 79 (Suppl), 119-141.

Rovati, C., Vanossi Este, S., Cima, L. and Milani, R. (1983) Recombination rates of the loci $M I, A g$, ac, and Mdh (1st Chr.) of Musca domestica L. Atti XIII Congr. Ital. Entmol., Trino, 519-526.

Rubini, P. G. and Franco, M. G. (1972) Localization of the male determining factor $M$ present in a strain of Musca domestica L. Genet. agr. 26, 217-232.

Rubini, P. G. and Palenzona D. (1967) Responce to selection for high number of heterochromosomes in Musca domestica L. Genet. agr. 21, 101-110.

Stevens, N. M. (1908) A study of the germ cells of certain Diptera with reference to the heterochromosomes and phenomenon of synapsis. J. Expt. Zool. 5, 350-378.

Sullivan, R. L. (1958) Sex limitation of several loci in the housefly. Proc. 10th Intern. Congr. Genet. 2, 282.

ToKUnaga, C. (1955) The presence of male determining factor in Aphiochaeta xanthina Speiser. Studies 2, 1-32. (Kobe College Press).

Tomita, T. and WADA, Y. (1985) VIM chromosomes of the housefly. Jpn. J. Genet. 60, 636.

WAGONER, D. E. (1967) Linkage group-karyotype correlation in the house fly determined by cytological analysis of X-ray induced translocations. Genetics 57, 729-739.

WAGONER, D. E. (1969) Presence of male determining factor found on three autosomes in the housefly, Musca domestica. Nature 223, 187-188. 